\title{
MEMÓRIAS DE ALFABETIZADORES MATEMÁTICOS EM PROCESSO DE FORMAÇÃO CONTINUADA
}

\author{
Fabio Colins da SILVA ${ }^{\mathbf{1}}$ \\ Universidade Federal do Pará - UFPA \\ formador.ufpa@gmail.com \\ Arthur Gonçalves Machado JÚNIOR ${ }^{2}$ \\ Universidade Federal do Pará - UFPA \\ agmj@ufpa.br \\ Tadeu Oliver GONÇALVES ${ }^{3}$ \\ Universidade Federal do Pará - UFPA \\ tadeuoliver@yahoo.com.br
}

\begin{abstract}
Resumo: Este texto é um recorte da dissertação intitulada "Saberes Docentes na/da Formação Continuada de Professores que Ensinam Matemática no Ciclo de Alfabetização”, que investigou os saberes docentes mobilizados na/da formação continuada de professores alfabetizadores. A pesquisa teve como contexto o Programa Federal Pacto Nacional pela Alfabetização na Idade Certa (PNAIC). O lócus da investigação foi o município de Marabá, Estado do Pará, Brasil. Os sujeitos deste estudo foram cinco professoras alfabetizadoras. A pesquisa foi realizada entre março de 2014 e janeiro de 2015. A construção das informações se deu a partir dos registros das atividades realizadas pelas professoras alfabetizadoras durante os encontros municipais de formação, dos seus relatórios de prática e dos seus relatos de experiência. A metodologia de análise utilizada foi a Análise Textual Discursiva. É possivel afirmar que, por meio das memórias, os professores em processo de formação podem mobilizar saberes necessários às práticas de alfabetização matemática.
\end{abstract}

Palavras-chave: Memórias. Formação

Continuada. Alfabetização Matemática.

\begin{abstract}
This text is an excerpt of the dissertation entitled "Knowledge Teachers in thelof the Continuing teacher training to teach Mathematics in Literacy Cycle", investigated the teaching knowledge mobilized in thelof the continued training literacy teachers. The research was context the Federal Program National Pact for Literacy in the Age One. The locus of the investigation was the city of Marabá, Pará State, Brazil. The subjects of this study were five literacy teachers. The survey was conducted between March 2014 and January 2015. The construction of the information was given from the records of the activities carried out by literacy teachers during the municipal formation meetings, their practice reports and their experience reports. The methodology used was the analysis Text Analysis Discourse. You can say that through the memories teachers training process can mobilize knowledge required for mathematical literacy practices.
\end{abstract}

Keywords: Memories. Continuing Education. Literacy Mathematics.

\footnotetext{
${ }^{1}$ Mestrado em Educação em Ciências e Matemáticas pela Universidade Federal do Pará, (2015). Professor Formador da Universidade Federal do Pará.

${ }^{2}$ Doutorado em Pós-Graduação em Educ. em Ciências e Matemáticas pela Universidade Federal do Pará, (2014). Professor Titular da Universidade Federal do Pará.

${ }^{3}$ Doutorado em Educação pela Universidade Estadual de Campinas, (2000). Membro do Conselho Diretor da FADESP da Universidade Federal do Pará , Brasil.
} 


\section{Introdução}

Partimos do pressuposto de que as memórias - a faculdade de conservar ideias e imagens, ou seja, lembranças e reminiscências de momentos importantes sobre o que estamos dispostos a narrar por meio das rememorações - podem ser utilizadas como uma ferramenta formativa. É nessa perspectiva que este artigo tem como objetivo apresentar um dos resultados de um curso de formação continuada de professores alfabetizadores em matemática.

As evidências da relação com o saber matemático manifestado pelas docentes foram construídas a partir da seleção de episódios, ou melhor, vestígios mnemônicos, significativos na constituição dessas professoras enquanto alunas das séries iniciais do Ensino Fundamental. Este artigo é um recorte da dissertação intitulada "Saberes Docentes na/da Formação Continuada de Professores que Ensinam Matemática no Ciclo de Alfabetização", que teve como objetivo investigar em que termos os saberes docentes são mobilizados a partir da formação continuada de professores alfabetizadores. Nesta pesquisa, uma das categorias de análise tratava da relação que as professoras alfabetizadoras tinham estabelecido com a matemática durante seu processo de alfabetização matemática.

$\mathrm{Na}$ construção do arcabouço teórico do estudo citado, utilizamos as pesquisas de Le Goff, que trata de uma concepção antropológica sobre a memória; a teoria dos saberes docentes experienciais mobilizados a partir das vozes das professoras, na perspectiva de Tardif; e, para discutir sobre a relação com o saber matemático, foi utilizado o estudo de Bernard Charlot, que possibilita analisar a construção do conhecimento matemático por meio das memórias.

A pesquisa teve como contexto o Programa Federal Pacto Nacional pela Alfabetização na Idade Certa (PNAIC). O lócus da investigação foi o município de Marabá, Estado do Pará, Brasil. Os sujeitos desse estudo foram cinco professoras alfabetizadoras, das quais duas serão citadas neste texto. A pesquisa foi realizada entre março de 2014 e janeiro de 2015. A construção das informações se deu, principalmente, a partir dos registros das atividades realizadas pelas professoras alfabetizadoras durante os encontros municipais, e dos seus relatos de experiência.

\section{Memória e formação}

Nos cursos de formação de professores em serviço, percebemos que os docentes sempre trazem situações vividas, seja como alunos, seja como profissionais da educação, para justificar muitas das suas práticas de sala de aula, pois é por meio de suas vozes que seus saberes materializam-se. Mas a que memórias estamos nos referindo? Nossa perspectiva de memória 
está pautada nos estudos antropológicos de Jean Jacques Le Goff. Para o autor, “o processo da memória no homem faz intervir não só a ordenação de vestígios, mas também a releitura desses vestígios." (LE GOFF, 2012, p. 406). É a partir desse pressuposto que faremos uma releitura das vivências de formação que contribuíram de maneira significativa na e para a formação das alfabetizadoras.

Assim as memórias que constituem este artigo são apresentadas por meio de um texto narrativo descritivo-analítico carregado de episódios mnemônicos. As narrativas selecionadas para esse texto têm ligação direta com as vivências/experiências de formação que levaram as professoras a estabelecer uma relação com o saber matemático condicionado à figura de um professor. $\mathrm{O}$ ato de narrar suas reminiscências auxiliou numa melhor compreensão da trajetória profissional dos sujeitos investigados. Por isso, narrar essas vivências/experiências possibilitou construir um objeto de pesquisa para esse estudo, a relação com o saber matemático. Sobre isso, Le Goff (2012, p. 407), afirma que “o ato mnemônico fundamental é o comportamento narrativo, que se caracteriza, antes de qualquer coisa, pela sua função social, pois se trata de comunicação a outrem de uma informação, na ausência do acontecimento ou do objeto que constitui o seu motivo.”.

Nesse sentido, no processo de constituição docente não podemos separar, em muitos casos, a vida pessoal da vida acadêmica e profissional, pois muito do que o professor é em sala de aula resulta do seu processo de formação humana. Para Nóvoa (2013, p. 14), não é possível reduzir a "vida escolar às dimensões racionais, nomeadamente porque uma grande parte dos atores educativos encara a convivialidade como um fator essencial e rejeita centração exclusiva nas aprendizagens acadêmicas.”. Separar a vida pessoal da vida profissional pode ocasionar um conflito sobre a própria identidade docente. Para Nóvoa (2013, p.15),

A crise de identidade dos professores, objeto de inúmeros debates ao longo dos últimos vinte anos, não é alheia a esta evolução que foi impondo uma separação entre o $e u$ pessoal e o $e u$ profissional. A transposição desta atitude do plano científico para o plano institucional contribuiu para intensificar o controle sobre os professores, favorecendo o seu processo de desprofissionalização.

Contudo, "o professor é a pessoa; e uma parte importante da pessoa é o professor." (NÓVOA, 2013, p. 15). As experiências pessoais implicam diretamente na escolha da profissão. Poderíamos nos perguntar: Por que me tornei professor? Na minha família tem algum professor? De que forma minhas ações pedagógicas foram influenciadas por minhas experiências de vida? Esses questionamentos podem ajudar no direcionamento de nossas ações docentes. Além disso, nos possibilitam a reflexão sobre como nossa trajetória de formação pessoal e profissional foi se constituindo. 
Desse modo, trazer as memórias, sejam elas individuais ou coletivas, para uma texto escrito, além de possibilitar uma melhor compreensão da relação entre o sujeito e o objeto pesquisado, constrói um diálogo entre narrador e interlocutor, que se entrelaçam na narrativa. Ou seja, uma forma de dialogismo. Uma polifonia de vozes/memórias. Portanto, é nesse processo polifônico que se deu a tessitura desse artigo.

\section{A construção das vozes}

Para que as memórias das alfabetizadoras fossem materializadas, fez-se necessário organizar, nos encontros formativos, atividades que possibilitassem às professoras falar sobre suas lembranças de como eram suas aulas de matemática quando estudavam as primeiras séries dos anos iniciais do Ensino Fundamental. Com isso, logo no primeiro contato direto com os docentes, foi aplicado um questionário para que pudéssemos construir as informações necessárias sobre o perfil das professoras alfabetizadoras. O questionário continha as seguintes perguntas:

- Qual é seu nome (opcional)?

- Qual é o seu vínculo trabalhista (efetivo ou contratado)?

- Qual sua formação acadêmica?

- Quanto tempo você tem de docência em turmas de alfabetização?

- Qual turma você está ministrando aulas?

Essas informações foram suficientes para desenhar o perfil das professoras alfabetizadoras. Elas eram todas do quadro efetivo da rede municipal de ensino de Marabá. Tinham entre 16 e 33 anos de experiência como professoras alfabetizadoras. No que se refere a suas formações acadêmicas, duas tinham o Ensino Médio Magistério, sendo que uma cursava a faculdade de Pedagogia. As demais eram licenciadas em Pedagogia e uma era especialista em Educação do Campo. Portanto, todas eram habilitadas para ministrar aulas na Educação Infantil e nos anos iniciais do Ensino Fundamental. Além disso, ministravam aula para alunos do ciclo de alfabetização, sendo que duas trabalhavam no meio rural com turmas multisseriadas. Ainda nesse mesmo encontro, além do questionário, desenvolvemos uma atividade de integração do grupo intitulada "O que quero levar na bagagem?".

Por meio dessa atividade, as alfabetizadoras poderiam falar sobre suas expectativas em relação ao curso de formação continuada em que estavam inseridas. As falas dos sujeitos foram registradas em um caderno de anotações. De um modo geral, as expectativas em relação ao curso eram as seguintes: aprender matemática para ensinar seus alunos; adquirir novos saberes 
do conteúdo matemático para sua prática de sala de aula; estabelecer uma nova relação com a matemática etc.

No segundo encontro em que estivemos reunidos com as alfabetizadoras, solicitamos que as mesmas fizessem um desenho que representasse como se deu o seu processo de alfabetização matemática. Elas deveriam rememorar como eram as suas aulas quando cursavam as séries iniciais do Ensino Fundamental, as práticas dos seus professores alfabetizadores, os recursos didáticos que eram utilizados nas aulas e a organização didática que era dada à aula. Além do desenho, tinham que escrever um texto justificando o motivo pelo qual aquela imagem representava seu processo de alfabetização matemática.

- Professoras, de posse de uma folha de papel A4 e lápis de cor, fazer um desenho que represente como foi sua alfabetização matemática, seus professores alfabetizadores e as aulas de matemática. Após desenhar, produzir um texto falando da sua relação com a matemática durante seus primeiros anos de escolarização.

Portanto, foi por meio desse processo de rememoração que os saberes da experiência foram manifestados através dos relatos orais e escritos sobre sua relação com as aulas de matemática quando eram alunas das séries iniciais do Ensino Fundamental. Com isso, surgiu a categoria de análise $A$ relação com o saber matemático. Para isso, foram selecionados as produções textuais e os desenhos construídos pelas professoras alfabetizadoras que possibilitou construir uma discussão acerca dos saberes da experiência mobilizados e a relação com o saber matemático.

\section{Na minha época, a aula de alfabetização matemática era assim...}

Para tratar da mobilização e da relação das alfabetizadoras com o saber matemático, recorreremos à teoria de Charlot (2000) sobre a relação com o saber. Para o autor, a mobilização de saberes dá-se a partir de uma relação que o sujeito estabelece com o mundo. Nesse sentido, "não há saber sem relação com o saber" (CHARLOT, 2000, p. 60). É esse movimento de saberes, por meio de uma relação com o mundo, com as experiências vividas e com as formas de comunicar-se com o outro que os discursos dos professores alfabetizadores foram analisados. Nesse sentido apontado por Charlot, construir saberes requer certo domínio da relação que estabelecemos com o outro, com o mundo e consigo mesmo. Tudo isso alicerçado por nossas experiências de vida. É nesse sentido que a professora Antônia manifesta, por meio de seu discurso, suas primeiras relações com o saber matemático condicionado pela instituição escolar e por seu professor das séries iniciais. 
A professora Antônia tinha 16 anos de experiência com alfabetização de crianças na educação infantil e nos anos iniciais do ensino fundamental. Ela atuava em turmas multisseriadas ( $1^{\circ}$ ao $3^{\circ}$ ano do ensino fundamental). A escola em que trabalhava era localizada no meio rural. Segundo a professora, suas condições de trabalho não eram muito favoráveis, pois faltava apoio técnico-pedagógico e infraestrutura na sala de aula, mas, mesmo assim, realizava um bom trabalho. Era formada em pedagogia e possuía especialização em Educação do Campo. Porém, relatou que ainda precisava aprender muito, principalmente, sobre alfabetizar crianças em turmas multisseriadas. Sobre sua experiência com a matemática, disse que não foi muito boa, mesmo porque não se ensinava matemática como se ensina hoje.

Quando eu era aluna das séries iniciais, tive um professor muito tradicional e rígido em sua forma de ensinar, mas com esse tradicionalismo foi um bom professor. A matemática, que é uma disciplina muito difícil de ser entendida, por isso, para ser um bom professor de matemática, é preciso gostar da disciplina. Eu não gosto muito de matemática, minhas capacidades são poucas. Porque eu acho difícil as operações que envolve muitos cálculos. Em matemática, não acho nada fácil. Mas, para ser um bom professor de matemática, precisa dominar bem a disciplina e usar uma metodologia diversificada. Nas minhas aulas de matemática, eu ficava muito nervosa só de ver o professor entrando na sala. $\mathrm{O}$ professor explicava e eu não entendia. Quando aprendo alguma coisa de matemática fico muito feliz e, penso eu, que é mais um obstáculo superado (Produção textual da professora Antônia).

No discurso dessa professora alfabetizadora, podemos perceber sua relação com o saber matemático. Enfatiza a prática tradicional de ensinar do seu ex-professor, mas a considera eficiente: "mas com esse tradicionalismo foi um bom professor". Isso fica mais evidente quando afirma que um bom professor de matemática é aquele que sabe o conteúdo e tem uma boa metodologia. Diante do exposto, pode-se afirmar que sua relação com a matemática deu-se inicialmente por meio da imagem de um docente que dominava o conteúdo matemático. Um professor conteudista.

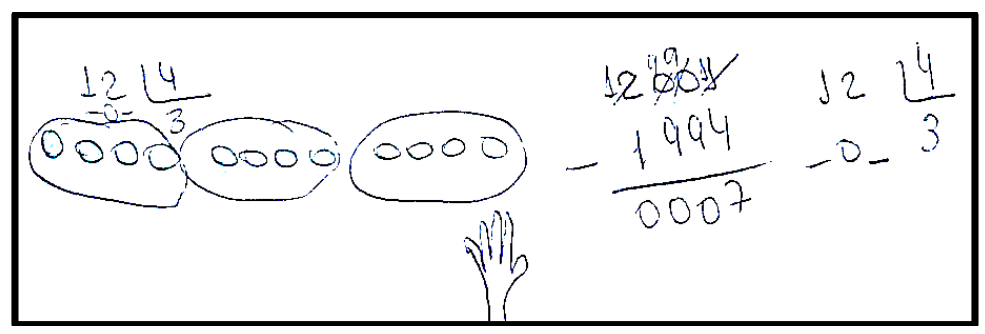

Figura 1 - Desenho da professora Antônia

Fonte: Registro da professora Antônia

Ao explicar o desenho, a professora relatou que:

Na minha época, as aulas de matemática não eram como as de hoje. Hoje temos outros recursos [...]. Quando eu estava nas séries iniciais não aprendia e nem entendia a matemática. Eu sabia somente o suficiente para passar de ano, de forma mecânica e com pequenas estratégias (Produção Textual). 
$\mathrm{Na}$ imagem feita pela professora, percebe-se a ênfase na aplicação de algoritmos. Ou seja, um professor que precisa dominar a técnica. Um docente que precisa saber matemática. Porém, no desenho da mão levantada, esse ensino deve oportunizar um diálogo entre professor e aluno. Isso fica mais evidente no discurso da alfabetizadora quando afirma: "O professor explicava e eu não entendia". Essas experiências refletem uma relação com o saber matemático a partir de uma prática docente focada somente no conteúdo. Possivelmente, a forma como a alfabetizadora estabeleceu suas relações iniciais com a matemática poderá influenciar na sua prática como professora que ensina matemática nos anos iniciais do Ensino Fundamental. Isso fica evidente quando tem o cuidado de justificar o seu não aprender, ou seja, sua relação com o saber por meio da prática do outro, o seu professor, assim como uma relação consigo mesma.

Sobre isso, Charlot (2000, p. 60) afirma que "o sujeito de saber desenvolve uma atividade que lhe é própria: argumentação, verificação, experimentação, vontade de demonstrar, provar validar. Essa atividade é também ação do sujeito sobre ele mesmo. Essa atividade implica ainda uma forma de relação com os outros". Isso aparece quando a alfabetizadora argumenta sobre o seu insucesso nas aulas de matemática: "Quando eu era aluna das séries iniciais, tive um professor muito tradicional e rígido em sua forma de ensinar e não entendia e nem aprendia matemática.” (Produção textual da professora Antônia).

Para Tardif (2014), esses saberes, aqui presenciados no discurso dessa professora, são recorrentes da seguinte fonte social: sua educação, no sentido lato. Consequentemente, essas experiências vivenciadas durante sua formação primária vão refletir nas suas práticas de alfabetização matemática. No seu discurso - "A matemática que é uma disciplina muito difícil de ser entendida, por isso, para ser um bom professor de matemática é preciso gostar da disciplina" - essas marcas ideológicas vão se manifestando no seu relato/discurso.

Os saberes experienciais presentes no discurso da professora Antônia refletem sua relação com a matemática: "Em matemática, eu não acho nada fácil”. Uma relação em que não se sente preparada para ensinar matemática, falta conteúdo. Mas, reconhecendo suas limitações, dispõe-se a querer aprender e, quando aprende, sente-se feliz: "Quando aprendo alguma coisa de matemática, fico muito feliz e, penso eu, que é mais um obstáculo superado.”. Para Tardif (2014, p. 54), “os saberes experienciais surgem como núcleo vital do saber docente, núcleo a partir do qual os professores tentam transformar suas relações de exterioridade com os saberes em relações de interioridade com sua própria prática.”.

Ao afirmar que a matemática é difícil e que, quando aprende algo da matemática, ou seja, passa a estabelecer uma relação com o saber matemático, sente-se "feliz", está mostrando, 
por meio de uma atividade ideológica, que a mobilização de saberes não pode ocorrer de forma isolada das outras relações estabelecidas: família, sociedade, escola, professores, colegas etc., ou seja, a relação da professora alfabetizadora com o saber matemático, segundo Charlot (2000):

[...] não poderia ser compreendida sem que se a apreenda sob essa forma específica de relação com o mundo. Em outras palavras, não se poderia, para definir a relação com o saber, partir do sujeito de saber (da razão); pois, para entender o sujeito de saber, é preciso apreender sua relação com o saber. (CHARLOT, 2000, p. 61).

São dessas vivências formativas que o professor vai construindo sua relação com o saber e mobilizando saberes necessários à docência, pois "a experiência do professor não deixa de ser uma coisa pessoal e, acima de tudo, privada." (GAUTHIER, 2013, p. 33).

Esses saberes também estão presentes no discurso da professora Benedita. Ela tinha 20 anos de experiência como alfabetizadora na Educação Infantil e nos anos iniciais do Ensino Fundamental. Tinha formação em Pedagogia e lecionava para alunos do $1^{\circ}$ ano do Ensino Fundamental de uma escola da rede municipal de ensino. Seu discurso traz marcas de como foi sua trajetória formativa nas séries iniciais e sua relação com a matemática e com o professor que ensina essa disciplina.

Acho a matemática um pouco difícil. Preciso me dedicar melhor a essa disciplina. Tenho um pouco de dificuldade quando envolve números e letras. Pois pra mim, um professor que ensina matemática precisa se especializar na área. Quando o assunto é números naturais, eu acho mais fácil. Eu gostaria de aprender mais matemática para fazer com que meus alunos aprendam mais. Queria aprender novas metodologias. Métodos para que os conteúdos ficassem mais claros. Na época em que eu estudava a $1^{\mathrm{a}}$ série, meu professor não explicava direito e então eu não conseguia aprender bem o conteúdo. Acho que é por isso que até hoje não sei muita matemática. Então, espero aprender mais matemática nesse curso para que eu possa alfabetizar meus alunos em matemática (Produção textual da professora Benedita).

Apesar de a professora Benedita, mesmo fazendo juízo de valor sobre o que é ser um bom professor que ensina matemática, trazer marcas discursivas sobre como se deu sua relação com o saber matemático, uma relação, também, é estabelecida por um professor que ensinava matemática sem domínio do conteúdo, e isso passou a refletir na sua prática como alfabetizadora em matemática. Isso fica explícito ao afirmar que espera do curso "aprender mais matemática nesse curso para que eu possa alfabetizar meus alunos em matemática.”.

Essa relação fica mais explícita ao afirmar que o fato de não saber matemática hoje é decorrente de não ter recebido uma boa alfabetização matemática: "Quando eu era aluna meu professor não explicava direito e então eu não conseguia aprender bem o conteúdo. Acho que é por isso que até hoje não sei muita matemática". Nesse trecho do discurso da 
professora, percebe-se um confronto entre o sujeito de saber e seu professor que ensinava matemática. Com isso, o saber mobilizado/produzido pela professora alfabetizadora é resultante do "confronto a outros sujeitos, é construído em 'quadros metodológicos'. Pode, portanto, 'entrar na ordem do objeto'; e tornar-se, então, 'um produto comunicável', uma informação disponível para outrem." (CHARLOT, 2000, p. 61).

Sobre isso, Tardif (2014, p. 65) afirma que os saberes docentes advindos das experiências são coerentes no que concerne sua lógica pragmática e biográfica, "assim como as diferentes ferramentas de um artesão, eles fazem parte da mesma caixa de ferramentas, pois o artesão que os adotou ou adaptou pode precisar deles em seu trabalho. Isso ocorre mesmo com os saberes que fundamentam o trabalho dos professores.".

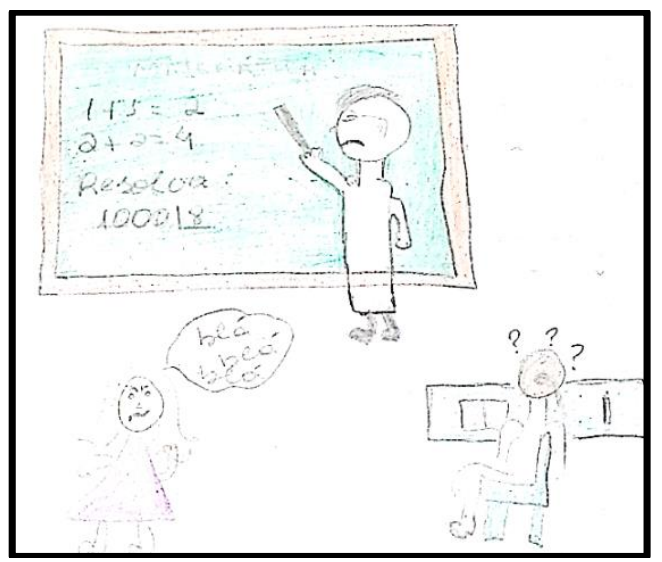

Figura 2 - Desenho da professora Antônia

Fonte: Registro da professora Antônia

Ao justificar seu desenho que representa sua relação com a matemática quando era aluna das séries iniciais, relata que:

\footnotetext{
Esse desenho significa como eram as minhas aulas de matemática nas séries iniciais. A maioria dos meus professores começava com uma explicação muito fácil, mas na hora de passar os exercícios apareciam problemas muito difíceis, diferentes dos que eles explicavam-nas aulas. Não havia dinâmica nem jogos (Sinopse do discurso).
}

O desenho produzido pela professora versa sobre sua relação com as aulas de matemática em que não compreendia o assunto explicado pelo professor. Dessa relação não muito harmoniosa com a matemática, especificamente, com as metodologias de ensino de matemática, a professora deseja aprender maneiras de propor um ensino de matemática capaz de fazer com que seus alunos aprendam o conteúdo: "Queria aprender novas metodologias. Métodos para que os conteúdos ficassem mais claros”. Esse querer pode ser compreendido como uma forma de se desenvolver profissionalmente por meio dos cursos de formação continuada, por exemplo. Para Tardif (2014, p. 68), “o desenvolvimento do saber profissional é associado tanto às suas fontes e lugares de aquisição quanto aos seus momentos e fases de construção.". 
$\mathrm{Na}$ imagem acima, representa-se, muito claramente, a relação estabelecida pela professora com os outros sujeitos durante a construção do saber matemático. É nessa perspectiva que Charlot (2000) discute sobre a relação do saber por meio de um processo de relações internas e de confrontos interpessoais. Por isso, ele considera o saber como um produto e um resultado dessas relações. Além disso, a professora assume que precisa conhecer ainda mais a matemática. Estabelecer uma relação mais estreita com esse campo do saber e que, para que isso seja possível, precisa dedicar-se mais, pois as experiências, como aluna, não foram suficientes para que tivesse os conhecimentos necessários para alfabetizar as crianças em matemática: "Preciso me dedicar melhor a essa disciplina. Tenho um pouco de dificuldade quando envolve números e letras”. Portanto, esses saberes, aqui manifestados no discurso da professora, são mobilizados de maneira temporal.

Portanto, as práticas das professoras alfabetizadoras estão intimamente ligadas às suas vivências de formação. Relacionadas com sua experiência de vida: social, familiar, escolar etc. Como afirma Gauthier (2013, p. 32), “aprender por meio de suas próprias experiências significa viver um momento particular, momento esse diferente de tudo o que se encontra habitualmente, sendo registrado como tal em nosso repertório de saberes.”.

\section{Considerações finais}

Para sintetizar as principais relações com o saber manifestadas nos discursos e nos registros pictóricos das professoras alfabetizadoras investigadas, criamos um diagrama que as representassem. Vejamos:

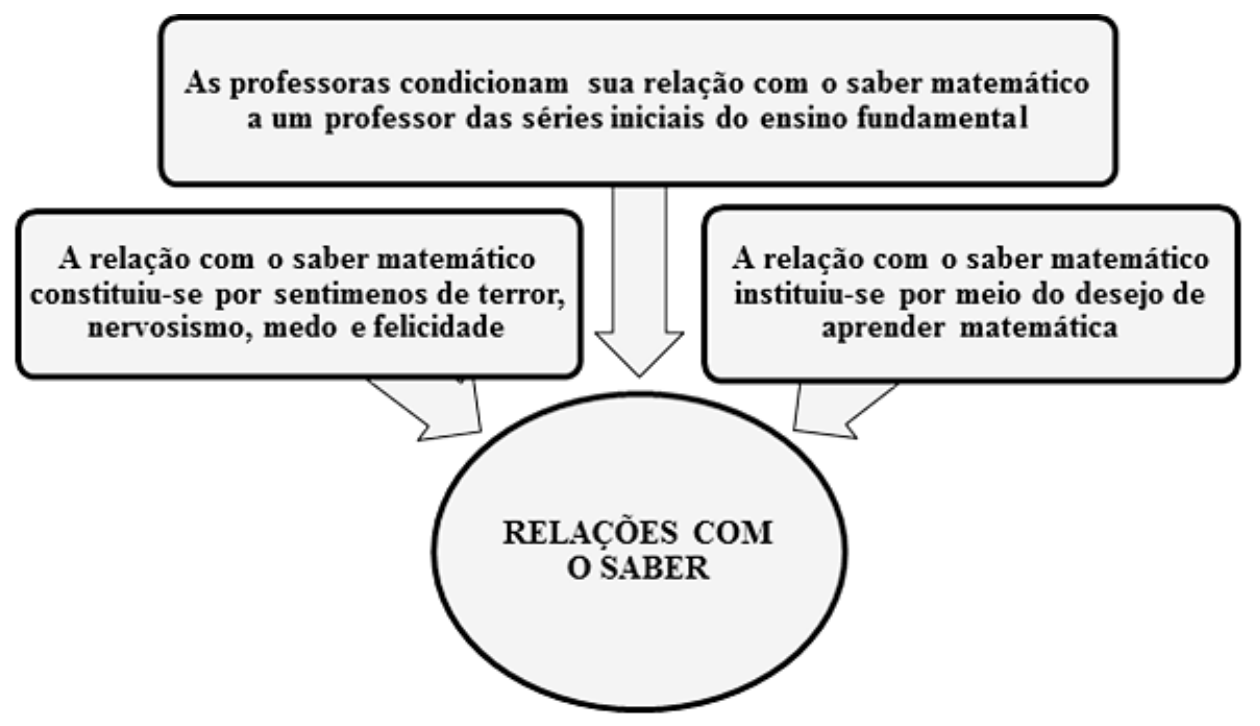

Fluxograma 1 - As principais relações com o saber Fonte: Do autor 
Nesse sentido, os saberes da experiência de vida pessoal e profissional é a base para a mobilização de outras categorias de saberes. Como afirma Gauthier (2013, p. 33), essas experiências tornam-se "a regra e, ao ser repetida, assume muitas vezes a forma de uma atividade de rotina. Que se trate de um momento único ou repetido infinitas vezes, a experiência do professor não deixa de ser uma coisa pessoal e, acima de tudo, privada". É a partir dessas vivências de formação que as professoras alfabetizadoras, nas suas práticas, foram estabelecendo juízos de valor para justificar e adotar determinada prática ou rejeitar outras.

Portanto, as relações com o saber, especificamente o saber matemático, manifestaramse baseados nos discursos das professoras alfabetizadoras, por meio de uma relação com o mundo, como um conjunto de relações do sujeito com um objeto, um conteúdo, uma atividade interpessoal, um lugar (por exemplo, a escola), uma pessoa (por exemplo, o professor que ensina matemática), uma situação, um contexto, todas ligadas ao desejo de aprender e ao saber. Todas essas relações estão diretamente ligadas às experiências de vida, escolar e profissional. Porém, os saberes mobilizados pelas alfabetizadoras podem emergir da/na prática pedagógica.

\section{Referências}

CHARLOT, Bernard. Da Relação com o Saber: elementos para uma teoria. Porto Alegre: Artmed, 2000.

GAUTHIER, Clermont. et ali. Por uma Teoria da Pedagogia: pesquisas contemporâneas sobre o saber docente. 3. ed. Ijuí: Unijuí, 2013.

LE GOFF, Jacques. História e Memória. Trad. Irene Ferreira. Campinas, SP: Unicamp, 2012. NÓVOA, António (Org.). Vida de Professores. 2. ed. Trad. Maria dos Anjos Caseiro. Porto: Porto Editora, 2013.

TARDIF, Maurice. Saberes Docentes e Formação Profissional. 16. ed. Petrópolis, RJ: Vozes, 2014. 